\title{
Affordances indutoras de inovação no jornalismo móvel de revistas para tablets ${ }^{1}$
}

\section{Adalton dos Anjos Fonseca}

Doutorando, Universidade Federal da Bahia, Salvador, BA, Brasil

adalton.anjos@gmail.com

\section{Suzana Oliveira Barbosa}

Doutora, Universidade Federal da Bahia, Salvador, BA, Brasil

suzana.barbosa@gmail.com

\section{Resumo}

Este artigo examina a inovação no jornalismo móvel a partir do conceito de affordance aplicado no estudo de revistas para tablets em três momentos definidos, entre 2010 e 2016. Criouse uma ferramenta metodológica de análise com o objetivo de explorar os quatro conjuntos de affordances identificados: operação, coleção, compartilhamento e multimidialidade. A partir destes grupos, pontuou-se a emersão de affordances inovadoras possibilitadas pelos recursos e funcionalidades dos tablets e que também permitem interações inéditas ou renovadas na relação entre usuários e revistas. Entre elas estão: ouvir, assistir, jogar, pesquisar, armazenar. A comparação entre as revistas analisadas que mais se destacaram pela inovação também revelou uma tendência de estabilização de um formato para exploração dos recursos e funcionalidades do tablet, apesar de reconhecermos que há possibilidades ainda não exploradas pelos produtos que têm o potencial de induzir mais inovações.

\section{Palavras-chave}

Jornalismo Móvel. Affordances. Inovação. Revistas para tablets.

\section{Introdução}

Tratar da inovação no jornalismo significa trabalhar com uma agenda de estudos com diversas possibilidades de abordagens e metodologias de pesquisa (FONSECA, 2015; TRAPPEL, 2015; GRUBENMANN, 2013; FRANCISCATO, 2010; MACHADO, 2010). O próprio

\footnotetext{
1 Trabalho prévio inicialmente apresentado no GT Estudos de Jornalismo do XXV Encontro Anual da Compós, realizado na Universidade Federal de Goiás (Goiânia), de 7 a 10 de junho de 2016.
} 
tema da inovação é discutido a partir de várias tradições de investigação - desde a antropologia, a história e a sociologia, até a economia e a comunicação - o que exige do pesquisador em ciências sociais um recorte preciso do seu objeto de estudo e um olhar amplo o suficiente para contemplar a transdisciplinaridade do fenômeno (GODIN, 2008; FAGERBERG, 2003; ROGERS, 2003; SCHUMPETER, 1997; KLINE, ROSEMBERG, 1986; FREEMAN, 1979). Quando se trata do jornalismo, por exemplo, este conceito pode se referir às mudanças no processo de produção (SILVA, 2013), às alterações nas rotinas e perfis profissionais (BAUMANN, 2013; PAVLIK, 2008; DAILEY, DEMO, SPILLMAN, 2005), às transformações tecnológicas e ao lançamento de novos produtos e formatos jornalísticos (PALACIOS et al., 2014, 2015; BARBOSA, 2007, 2014). É preciso, portanto, estar atento às vertentes tecnológicas, organizacionais e sociais para a definição das pesquisas acerca da inovação, como aponta Franciscato (2010).

A partir desses autores, entendemos a inovação no jornalismo como um fenômeno de múltiplas dimensões em um determinado contexto, a fim de renovar/criar novos produtos/serviços ou novas formas de produção e consumo (FONSECA, 2015). É preciso destacar que um conjunto de elementos deve estar articulado para o andamento do processo que depende de desenvolvimentos técnicos, legislação, além dos anunciantes, instituições de ensino, profissionais envolvidos, entre outros.

0 artigo em tela propõe-se a examinar as inovações no jornalismo móvel de revistas para tablets tendo como referência três momentos específicos, definidos entre 2010 e 2016. Entendemos o jornalismo móvel como um conceito que aborda as relações e dinâmicas da prática jornalística nas etapas de apuração, edição, circulação e recirculação de conteúdos (CUNHA, 2015; FONSECA, 2015; SILVA, 2015; PALACIOS et al., 2014; CANAVILHAS, SANTANA, 2011). As justificativas para a escolha desta plataforma se dão pela importância do dispositivo para a indústria da comunicação móvel (47\% dos usuários de internet o fazem através do tablet, segundo pesquisa de 2014 da Global Web Index) e dos seus recursos e funcionalidades, que renovam, transformam e intensificam elementos representativos do jornalismo de revista ${ }^{2}$.

As revistas para tablets consistem em publicações que: (1) descendem de versões impressas ou são exclusivas para a plataforma móvel; (2) investem em uma estética visual e textual apurada; (3) geralmente são segmentadas (SOUZA, 2013); (4) são materializadas sob

\footnotetext{
2 Segundo Benetti (2013), a revista é um objeto jornalístico capaz de instaurar experiências sobre o presente através de um discurso que explora recursos linguísticos e visuais em confluência com a deontologia jornalística para explorar a "ontologia das emoções", ou seja, para ativar prazeres sinestésicos por meio de textos escritos ou imagens.
} 
o formato de aplicativos e seguem o padrão de funcionamento básico adotado pelo ecossistema móvel (AGUADO; FEIJÓo; MARTÍNEZ, 2011), como a operação por tactilidade, armazenamento na nuvem, compra online em lojas de aplicativos (AGUADO, 2013); (5) têm periodicidade; e (6) são colecionáveis (BENETTI, 2013).

A estratégia metodológica para elencarmos quais os aspectos inovadores que caracterizam as revistas jornalísticas para tablets está baseada na exploração do conceito das affordances, cunhado na área da psicologia pelo estadunidense James Gibson, em 1966, e desenvolvido por diversos autores, como Palacios et al. (2015), Norman (2002), Hutchby (2001), McGrenere e Ho (2000) e Gaver (1991). A perspectiva permite uma análise de um objeto que valoriza a importância da tecnologia e a interferência dos indivíduos na apropriação e reconstrução dos artefatos. Criou-se uma ferramenta de análise de produtos jornalísticos para apoiar o reconhecimento das affordances inovadoras nas publicações a partir da observação de três edições de três títulos de países distintos: National Geographic Magazine (Estados Unidos), Vis-à-Vis (Espanha) e Veja (Brasil), escolhidos por conta do seu potencial inovador (FONSECA, 2015; CUNHA, 2015).

\section{Sobre o conceito de affordance}

Com influências da Gestalt, o psicólogo James Gibson criou o conceito de affordance, em 1966, citando-o pela primeira vez no livro The senses considered as perceptual systems (GIBSON, 1966). Em 1979, ele tratou de modo mais detalhado as affordances ao explicar: "As affordances do ambiente são o que este oferta ao animal, o que provê ou fornece, seja para o bem ou para o mal.3" (GIBSON, 1979, p. 170, tradução nossa). Ele cita o exemplo de uma superfície com propriedades lisa, horizontal, estendida e rígida que permitirá ser utilizada como suporte, mas cujas possibilidades são ilimitadas.

Não há uma tradução do neologismo inglês para o português, mas o termo deriva do verbo to afford, que significa dar, dispor, gastar, arcar, permitir, entre outros. Gibson incorpora às discussões das affordances a interação homem e natureza e abre caminho para discorrer sobre a ação humana na mudança de formatos de objetos do meio ambiente (JONES, 2003). Do ponto de vista das discussões sobre a inovação em tradições de pesquisa como a antropologia e a sociologia, percebemos que essas invenções técnicas que permitiram ao homem sair de uma vida primitiva e facilitaram a tarefa de conseguir comida,

\footnotetext{
3 No original: "The affordances of the environment are what it offers the animal, what it provides or furnishes, either for good or ill." (GIBSON, 1979, p. 170).
} 
controlar fogo e ver a noite foram possíveis por conta da nossa capacidade de revelar affordances de objetos. A partir disso, chega-se à noção de affordances não aparentes - ou ocultas (MCGRENERE; HO, 2000), as quais, como afirmam Palacios et al. (2015), são elementos com maior potencial indutor de inovações, principalmente no jornalismo móvel.

Com a morte prematura de Gibson, em 1979, algumas propostas necessárias para refinar o conceito foram realizadas por outros estudiosos de diversas áreas. A implicação disso foi que uma série de desvios nas interpretações da premissa inicial do psicólogo emergiu nos estudos subsequentes. 0 designer Donald Norman é um dos principais autores citados em meio à controvérsia que surgiu a partir das apropriações sobre o termo.

Em Norman (2002), as affordances "[...] se referem às propriedades percebidas e atuais de uma coisa, principalmente aquelas qualidades fundamentais que determinam como uma coisa poderia ser utilizada [...] 4" (NORMAN, 2002, p. 9, tradução nossa). Para o designer, as affordances podem ser reais, quando não precisam ser aprendidas e percebidas, quando demandam modelos conceituais e as restrições (constraints) para apontar como a coisa funciona.

Um ponto de discordância entre Norman e Gibson está relacionado à ideia de falsas affordances, que aparecerá em alguns trabalhos de outros autores, como em Gaver (1991). Norman (2002) pontua que as falsas affordances ocorrem quando as pessoas erram em uma ação. Em Gibson (1979), a ideia da "desinformação em affordances" é o elemento equivalente ao das falsas affordances. Para o psicológico, as affordances existem ou não existem, ou seja, não obedecem ao binarismo verdadeiro ou falso.

McGrenere e Ho (2000) tentam superar a questão das affordances falsas de Norman ao apresentarem a ideia das affordances aparentes ou não aparentes (ocultas). Ao explorarem esta proposta, Palacios et al. (2015) defendem que as inovações no jornalismo móvel são induzidas por affordances não aparentes/ocultas, ou seja: dependem da capacidade de percepção, decisão e repertório cultural de produtores e consumidores de conteúdo. Já as aparentes são aquelas percebidas com maior facilidade porque emulam affordances anteriores. No caso dos conteúdos produzidos para tablets, imitam ou até remedeiam (BOLTER; GRUSIN, 2000) produtos anteriores.

A conclusão da controvérsia entre as discussões de Gibson e Norman sobre as affordances se dá com a admissão deste que a definição de affordances percebidas precisava

\footnotetext{
4 No original: "[...] refers to the perceived and actual properties of the thing, primarily those fundamental properties that determine just how the thing could possibly be used [...]" (NORMAN, 2002, p. 9).
} 
ser revista. Para tal, Norman apresentou, em 2008, o conceito de significante (signifiers), como algo entre o mundo físico e o social que pode ser interpretado.

Diante das distintas compreensões sobre o conceito de affordance, apontadas de modo sintético neste artigo, adotamos aqui a seguinte definição operacional:

As affordances emergem da relação entre usuário e objeto, em um contexto cultural e estão sujeitas a operações interpretativas e multissensoriais. Elas são sugeridas por meio da interface pelo designer, mas também são apropriáveis e, por isto, imprevisíveis. Podem ser aparentes ou ocultas, contudo, é neste último grupo que concentram as inovações mais complexas. (FONSECA, 2015, p. 93)

\section{Affordances, comunicação, inovação e jornalismo para dispositivos móveis}

Quando Norman (2013) pediu aos designers que esquecessem as affordances, ele afirmou que o conceito de Gibson não era tão adequado para análises de objetos virtuais. Seguimos posição menos radical e pontuamos que, na verdade, a observação de affordances trata-se de uma tarefa que exige um olhar mais amplo sobre o dispositivo ${ }^{5}$ e toda a cadeia de mudanças que emergem a partir da relação dele com diversos membros do sistema social, como entre produtores e consumidores, além das repercussões no próprio conteúdo.

Um exemplo disso vem da classificação das propriedades representativas do computador, como um novo meio, empreendida por Murray (2012). A autora afirma que este dispositivo é enciclopédico, porque contém e transmite muitas informações; espacial, porque cria espaços de navegação que podem ser não-lineares; procedimental, porque representa comportamentos condicionados a um conjunto de regras; e participatório, porque depende de scripts de ações de humanos e máquinas. Portanto, pode-se estudar as características da máquina e/ou do conteúdo configurado para circular através da máquina (o computador e, acrescentamos, o tablet ou o smartphone).

A dinâmica do jornalismo móvel segue a lógica de outros produtos para esta plataforma fundamentada no formato dos aplicativos - uma fusão entre conteúdos e softwares que favorece a monetização. Os aplicativos são bastante diversificados e

\footnotetext{
5 O termo dispositivo já era discutido desde Michel Foucault na década de 1970, quando ele reflete sobre tema em uma entrevista à revista francesa Dits et ecrits (COLAS et al., 1977) e na obra Microfísica do poder (1979). 0 conceito é um conjunto heterogêneo, que une uma rede de elementos linguísticos e não linguísticos (discurso, instituições e leis, por exemplo). 0 dispositivo tem função e estabelece relação de poder ao se apresentar como qualquer coisa que possa capturar, orientar, determinar, controlar e assegurar condutas, opiniões e discursos dos seres viventes. Segundo Agamben (2005), teríamos vários exemplos de dispositivos na contemporaneidade, além de computadores e celulares, como as prisões, as fábricas, o panóptico, a caneta, a literatura e a linguagem.
} 
fragmentados, já que o ecossistema móvel tem como uma de suas affordances a participação de desenvolvedores individuais e independentes na produção de conteúdo, além dos grandes grupos tradicionais da indústria cultural. Este aspecto tem como ponto positivo o estímulo às inovações espontâneas e, com isso, a possibilidade de uma diversidade maior de produtos (AGUADO, FEIJÓO, MARTINEZ, 2011; AGUADO, GÜERE, 2013).

Este cenário da comunicação móvel é caracterizado por Silva (2015) pela utilização de dispositivos que permitem a mobilidade física (pelo tamanho) e informacional (pela computação na nuvem), pela portabilidade e ubiquidade. Ainda segundo ele, o conceito de jornalismo móvel se relaciona a:

[...] utilização das tecnologias móveis digitais e de conexões de redes sem fio pelo repórter na prática jornalística contemporânea visando ao desenvolvimento das etapas de apuração, produção e distribuição de conteúdos do campo ou transmissão ao vivo [...] (SILVA, 2015, p. 11).

Canavilhas e Santana (2011) apresentam alguns aspectos importantes dos produtos jornalísticos produzidos para plataformas móveis como a acessibilidade, instantaneidade, multimidialidade, hipertextualidade, interatividade e globalidade. Além disto, eles defendem que a combinação destes recursos nos produtos jornalísticos tem um potencial econômico que pode responder às dificuldades ligadas à sustentabilidade financeira das organizações jornalísticas.

Do ponto de vista da produção, uma série de mudanças também são conferidas e sintetizadas no conceito do Mobile Journalism (MoJo) - voltado para discussões sobre reportagens elaboradas e circuladas com o uso de smartphones, que são capazes de gravar vídeos e áudios, fotografar, permitir a criação de textos, editar e publicar este material através de aplicativos específicos instalados no aparelho e conexão com a Internet por WiFi e rede 3G ou 4G (BURUM; QUINN, 2015). Com o olhar voltado para experiências nas redações de veículos tradicionais, Silva (2013) verifica que a prática do jornalismo móvel digital se dá com a exploração destes dispositivos para apuração, produção, edição, distribuição e compartilhamento ou transmissão ao vivo. Contudo, para a atual proposta de trabalho, o esforço está em investigar os produtos que são ofertados aos usuários por meio de um entre os vários tipos de dispositivos móveis ${ }^{6}$ - o tablet.

\footnotetext{
6 Em Palacios et al. (2015) e Aguado, Feijóo e Martinez (2011) são listados os vários tipos de dispositivos móveis como netbooks, smartphones, consoles, reprodutores, e-books conectáveis e tablets.
} 
Uma primeira questão que emerge diz respeito às revistas para tablets, produto jornalístico que estará no foco neste artigo. Fronteiras nebulosas nos obrigam a diferenciar estes produtos em relação aos aplicativos jornalísticos vespertinos autóctones para tablets. Isto porque as próprias organizações jornalísticas exploram o status de maior sofisticação da categoria revista na retórica persuasiva para se destacarem no mercado, como fez $O$ Globo com $O$ Globo a Mais ${ }^{7}$ e o agregador vinculado às redes sociais Flipboard. No Quadro 1, pontuam-se características específicas de cada tipo de produto.

Quadro 1 - Diferenças entre apps jornalísticos vespertinos e revistas para tablets

\section{Apps jornalísticos vespertinos}

Periodicidade diária (em geral, de segunda a sexta);

Público sem segmentação;

Geralmente fatos efêmeros;

Não-colecionável e

Informa os principais eventos do dia

Ex: O Globo a Mais Diário do Nordeste Plus e La Press+ (Canadá).

\section{Revistas para tablets}

Periodicidade semanal, quinzenal, mensal ou trimestral;

Público geralmente é segmentado;

Temas não-perecíveis;

Colecionável e

Trabalha com a ontologia das emoções.

Ex: Veja, Vis-à-Vis, Bande à Part e National Geographic Magazine.

Fonte: Fonseca (2015, p. 83)

Existem características que definem o tratamento da informação pelos autóctones para tablets diários e que não são verificadas nas edições das revistas para tablet. Um exemplo é a cobertura dos fatos do dia com seções como "Cenas do dia" e "Últimas Notícias", no Estadão Noite (Estado de S. Paulo). Ou seja, a periodicidade diária é um forte elemento na apresentação da notícia nos vespertinos para tablets.

Esta propriedade das revistas também é importante para a dinâmica de produção, que se reflete no resultado destes produtos na versão para tablet. Verifica-se uma maior quantidade de reportagens em profundidade e, consequentemente, um produto mais extenso, uma maior variação na utilização de recursos audiovisuais e uma união mais complexa do design editorial (tamanho, colunas, tipografia, fotografia, infográfico, hierarquia, entre outros) e do digital (multimidialidade, hipertexto, interatividade, entre outros), por conta do maior tempo de criação.

Todas as características listadas das revistas para tablets têm algum vínculo com as particularidades do jornalismo de revista apresentadas por Benetti (2013), ao destacar as ontologias das emoções como recurso sinestésico fundamental neste formato jornalístico. A

7 Encerrado em maio de 2015, cerca de três anos após o seu lançamento. 
autora acaba também por revelar o que consideramos como algumas affordances previstas a partir da relação com o objeto revista e que podem ser estendidas ou adaptadas na versão para dispositivo móvel:

Pode-se afirmar que o jornalismo de revista explora uma ontologia das emoções pela ativação: do prazer sensorial de folhear uma coleção de páginas agrupadas, coloridas e com papel de textura agradável; da fruição estética de imagens belas, dramáticas, chocantes, intensas, hiper-reais; dos relatos que provocam emoções universais, como o medo, desejo, curiosidade, estupefação, alegria, melancolia, inveja, desassossego, solidão, do movimento entre o mundo concretamente vivido e o mundo apenas imaginado das histórias de outras pessoas, em outros lugares. (BENETTI, 2013, p. 55).

A partir da próxima seção, passamos à análise das affordances inovadoras em revistas para tablets, tendo como ponto de partida ações como as listadas acima e a busca por novas características. Folhear, colecionar, tocar e sentir texturas, fruir esteticamente, se emocionar, ler, ver, dobrar, emprestar, recortar e riscar são algumas affordances previstas pela versão impressa das publicações. Cabe, agora, descobrir quais as alterações/adaptações e inovações presentes nas revistas para tablets e pontuar algumas implicações destas modificações do ponto de vista jornalístico.

\section{Metodologia de análise das affordances inovadoras em revistas para tablets}

Para enfrentar um dos principais desafios da investigação sobre a inovação (como mensurá-la?), aplicou-se ferramenta específica de análise da inovação (FONSECA, 2015) com o objetivo de explorar os quatro conjuntos de affordances identificados: operação, coleção, compartilhamento e multimidialidade. 0 instrumento contém 26 perguntas ${ }^{8}$ que devem ser respondidas no formato ocorrência ("1") e não-ocorrência ("0"). 0 avaliador precisa ter uma experiência com o produto por inteiro - realizar o download do aplicativo e navegar pelo mesmo, comprar a edição da revista e consumi-la. Sugerimos a realização de anotações livres.

As perguntas escolhidas para compor a ferramenta serão capazes de revelar a emergência de affordances originárias a partir da relação entre o usuário e a revista. Diante

\footnotetext{
8 As perguntas relativas à coleção só podem ser aplicadas em edições da revista publicadas após a data da última atualização do aplicativo. Não é possível avaliar a performance do aplicativo em versões passadas, uma vez que são substituídos. No caso das publicações que fizeram parte do corpus maior da pesquisa do mestrado, a análise nos dois primeiros números conteve 21 perguntas.
} 
destes resultados, será possível realizar comparações entre os títulos e em diferentes momentos.

Quadro 2 - Roteiro para análise das affordances em revistas para tablets

\begin{tabular}{|c|c|c|c|}
\hline \multirow{3}{*}{ 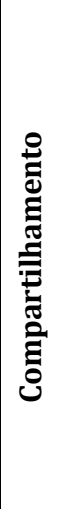 } & $\begin{array}{c}\text { Existem espaços na edição da revista para } \\
\text { compartilhamento de conteúdos por parte dos } \\
\text { leitores por e-mail? }\end{array}$ & \multirow{14}{*}{ 吾 } & $\begin{array}{c}\text { A abertura da revista contém vídeos, gifs ou } \\
\text { imagens animadas? }\end{array}$ \\
\hline & $\begin{array}{l}\text { Existem botões para o compartilhamento de } \\
\text { reportagens ou da edição completa nas redes } \\
\text { sociais? }\end{array}$ & & $\begin{array}{l}\text { A abertura da revista contém algum recurso } \\
\text { sonoro como música, fala ou algum ruído? }\end{array}$ \\
\hline & $\begin{array}{l}\text { Existe um campo integrado ao aplicativo que } \\
\text { permita o contato com o veículo, repórter ou } \\
\text { colunista, sem que seja preciso abrir outro } \\
\text { aplicativo de e-mail ou de rede social? }\end{array}$ & & $\begin{array}{l}\text { As reportagens exploram recursos como o } \\
\text { giroscópio para conteúdo extra ou melhorar a } \\
\text { experiência de consumo? }\end{array}$ \\
\hline \multirow{6}{*}{ 迅 } & $\begin{array}{l}\text { A edição permite marcar determinado trecho da } \\
\text { reportagem? }\end{array}$ & & Há gifs e animações? \\
\hline & $\begin{array}{c}\text { O aplicativo permite o acesso a todas as edições } \\
\text { digitais anteriores? }\end{array}$ & & Há desenhos, gráficos ou ilustrações? \\
\hline & $\begin{array}{l}\text { O aplicativo disponibiliza um sistema de busca } \\
\text { dentro de cada edição? }\end{array}$ & & Há quadros e tabelas interativos? \\
\hline & O aplicativo disponibiliza um sistema de busca em & & Há mapas e gráficos interativos? \\
\hline & todas as edições? & & \\
\hline & $\begin{array}{c}\text { O aplicativo disponibiliza uma função para excluir } \\
\text { um edição armazenada no dispositivo? }\end{array}$ & & Há newsgame? \\
\hline \multirow{5}{*}{ 选 } & $\begin{array}{l}\text { A revista se adequa a preferência de orientação de } \\
\text { leitura do usuário? }\end{array}$ & & $\begin{array}{l}\text { Há recursos de áudio como efeitos sonoros, } \\
\text { música ou discurso oral de forma complementar } \\
\text { ás reportagens? }\end{array}$ \\
\hline & $\begin{array}{l}\text { A edição utiliza elementos gráficos (setas, "+", } \\
\text { triângulos, entre outros) para indicar mudança na } \\
\text { telas ou para avançar no conteúdo? }\end{array}$ & & $\begin{array}{c}\text { Há vídeos de forma complementar, de produção } \\
\text { própria e que rode no próprio aplicativo? }\end{array}$ \\
\hline & $\begin{array}{c}\text { As reportagens exploram o recurso do scroll down } \\
\text { para navegação? }\end{array}$ & & Há fotos ou vídeos em $360^{\circ} ?$ \\
\hline & $\begin{array}{c}\text { As reportagens usam o deslizar para o carrossel } \\
\text { de imagens ou interação com objetos? }\end{array}$ & & $\begin{array}{l}\text { Há exploração de formatos como a realidade } \\
\text { aumentada ou realidade virtual? }\end{array}$ \\
\hline & $\begin{array}{c}\text { Os vídeos e objetos animados iniciam a } \\
\text { apresentação automaticamente sem necessidade } \\
\text { do play? }\end{array}$ & & Há hiperlinks externos nas reportagens? \\
\hline
\end{tabular}

Fonte: Baseado na ficha de apoio para a análise da inovação em revistas para tablet em Fonseca (2015, p. 243).

Para explorar uma variedade maior de formatos e exemplos de affordances indutoras de inovações, realizamos a análise de três revistas - National Geographic Magazine (NGM), Veja e Vis-à-Vis (VÀV) - de diferentes países - EUA, Brasil e Espanha, respectivamente - e 
com apropriações diversas do dispositivo. Em todas elas, as edições investigadas serão as primeiras lançadas no tablet, a mais recente no momento de produção deste artigo (primeiro número de 2016) e uma edição que fica exatamente na metade da trajetória de cada título.

Quadro 3 - Revistas e respectivas edições que compuseram a análise

\begin{tabular}{|c|c|c|c|c|c|}
\hline NGM & Edição & VÀV & Edição & VEJA & Edição \\
\hline Vol.219/№2 & Fev.2011 & №1 & Jan.2012 & №2182 & 08 Set.2010 \\
\hline Vol.223/№6 & Jun.2013 & №20 & Nov.2013 & №2320 & 08 Mai. 2013 \\
\hline Vol.229/№1 & Jan.2016 & №40 & Jan. 2016 & №2460 & 06 Jan. 2016 \\
\hline
\end{tabular}

Fonte: Elaborado pelos autores.

\section{Affordances inovadoras em revistas para tablets}

Os dados obtidos através da ficha de análise das affordances e expostos nos gráficos a seguir nos permitem identificar aspectos relacionados à evolução e ao estado atual de inovação em revistas para tablets. 0 primeiro deles é que, entre os três momentos, os produtos têm se desenvolvido e alguns títulos já se estabilizaram em um determinado formato, como a $N G M$ e a $V A ̀ V$. No caso do título espanhol, exclusivo para iPad, as mudanças ao longo deste intervalo de 40 edições, desde 2012, estão muito ligadas à disponibilização de novos recursos no dispositivo, como os vídeos que iniciam automaticamente. Mas as seções e recursos utilizados nas revistas estadunidense e espanhola foram bastante semelhantes, sobretudo entre o segundo e último número analisados.

Gráfico 1 - Ocorrência de características inovadoras nas revistas para tablets

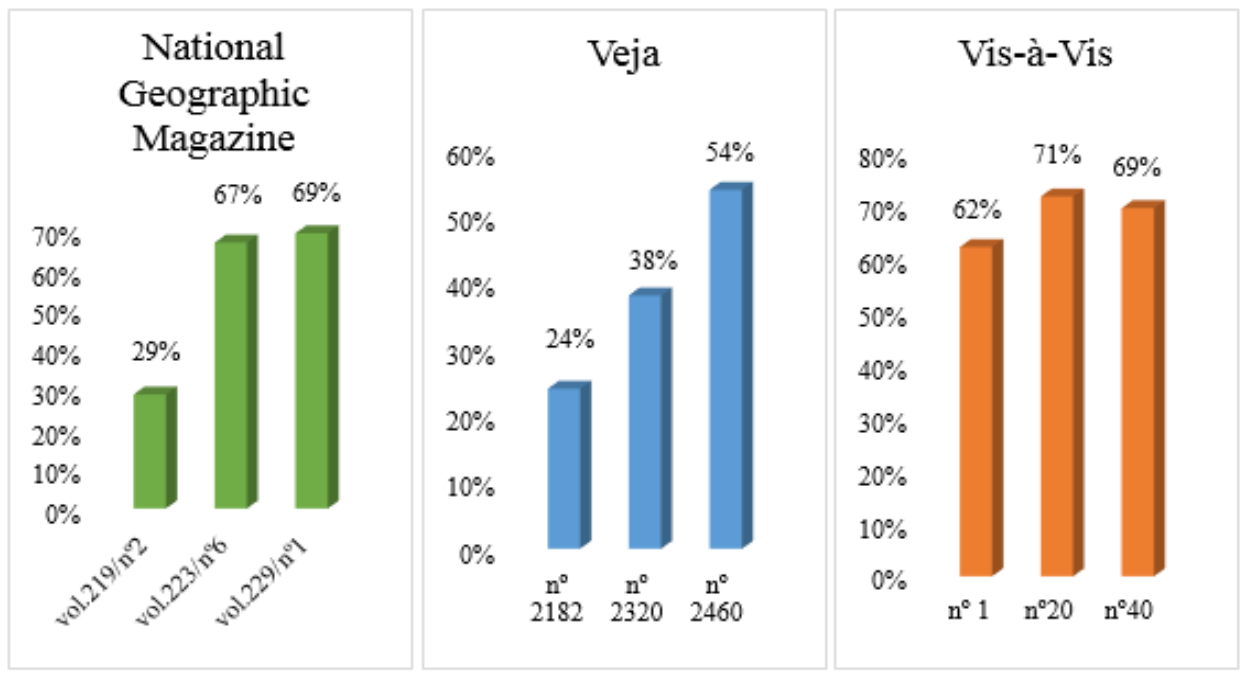

Fonte: Elaborado pelos autores. 
Outro ponto diz respeito às diferenças no desempenho entre publicações com periodicidade semanal (Veja) e as mensais; o maior tempo de produção é um dos fatores que ajudam a explicar as variações na apropriação de funcionalidades do tablet nas reportagens. 0 público e a localização também podem ser outras variáveis importantes no tipo de produto final oferecido. Já o preço da revista não foi um aspecto que indicasse qualquer potencialidade de inovação, uma vez que a $V A ̀ V$ é gratuita e os outros dois títulos são pagos.

\subsection{As mudanças na operação}

0 conjunto de affordances ligadas à operação das revistas deriva do próprio dispositivo, o tablet. Destacaremos dois recursos principais: a tactilidade e a nivelabilidade. A tactilidade, permitida através da tela sensível ao toque, é a principal forma de interação do usuário com os aplicativos a partir de gestos pré-definidos como o toque, duplo clique, rolar, deslizar, entre outros (PALACIOS; CUNHA, 2012). Já a nivelabilidade está ligada à exploração do sensor giroscópio, que permite a mudança de orientação de leitura.

As inovações que emergem a partir das affordances relacionadas à operação, sobretudo com a funcionalidade da tactilidade, são as mais comuns entre as revistas, porque muitas delas dizem respeito à interação básica com o aparelho. A análise deste aspecto se referia ao uso de elementos gráficos no apoio à mudança de tela, o uso do scroll down (rolar para baixo) para a navegação e do deslizar para o carrossel de imagens ou para fazer girar um objeto na tela. Verificamos a ocorrência em todas as revistas analisadas, com exceção da primeira edição da Veja no tablet (n⿳0 2182), que emulava a passagem de páginas como na versão impressa e não usava o scroll down.

Quanto à nivelabilidade, uma das questões se referia à possibilidade de escolha por parte do usuário da orientação de leitura da revista. Apenas a primeira edição da Veja no tablet ( $\mathrm{n}$ - 2182) concedia esta permissão; todas as outras fixavam o modo de leitura. A NGM sempre na horizontal (paisagem) e a VÀV e as edições subsequentes da Veja somente na vertical (retrato). Outra pergunta se referia ao uso do sensor para apresentar um conteúdo extra, como uma foto em tamanho maior ou proporcionar uma melhor experiência ao assistir um vídeo ou jogar, ao indicar que o usuário mude a posição do modo paisagem para

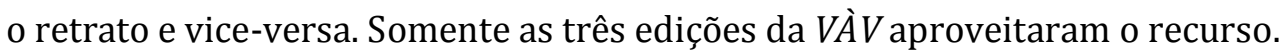

Por fim, o tópico das mudanças com relação à interação com as revistas ainda traz uma questão relativa a uma não-operação, no sentido de uma nova demanda para o usuário 
desvendar determinado conteúdo. 0 início automático de vídeos e objetos animados foi um aspecto presente apenas nas últimas edições das três publicações, de $2016^{9}$, antes dessas edições era preciso dar um comando com um toque simples em um botão de play para ativar qualquer conteúdo nas revistas. As edições analisadas, em janeiro de 2016, exploraram o recurso desde a capa em formatos narrativos diferentes, como veremos no tópico da multimidialidade.

\subsection{A coleção na nuvem}

Os processos de armazenamento das revistas para tablets seguiram a maior parte da dinâmica de funcionamento da computação na nuvem (cloud computing) e da aquisição e descarte dos aplicativos na plataforma móvel. Verificamos avanços e retrocessos nos processos de organização da coleção das publicações, uma das características representativas do conceito de revistas apontado por autores como Benetti (2013) e Tavares e Schwaab (2013).

As mudanças identificadas nas publicações perpassam por inovações que permitiram a redução do volume físico, assim como aconteceu com os e-books, o que facilita o transporte de uma coleção e o seu acesso a partir de qualquer lugar com conexão com a Internet. Além disso, temos a restauração de edições adquiridas e deletadas da memória do aparelho, a redução de barreiras geográficas para a compra de publicações de outros países e a recepção imediata do número.

Quanto aos retrocessos, entendemos que os desenvolvedores de aplicativos não agregaram soluções importantes para a memória oriundas da arquitetura de informação na Web. Scolari (2013) já apontava para este problema em suas conclusões em um artigo dedicado a caracterizar as revistas para tablets, denominada por ele de eMagazine. "[Os designers] se esqueceram de todos os ensinamentos sobre design interativo e a comunicação colaborativa aprendidos nos últimos 15 anos de World Wide Web” (p. 205). No aplicativo da Veja, por exemplo, verificamos a dificuldade para encontrar edições adquiridas pelo usuário. Isto porque elas ficam localizadas na mesma lista junto a todos os números já publicados pela revista, além das versões regionais de Belo Horizonte, Brasília, Rio de Janeiro e São Paulo; e de especiais, como os da Copa do Mundo de 2014, que circularam diariamente.

\footnotetext{
9 Desde 2014, revistas para tablets usam o vídeo automático em suas edições.
} 
Sobre a emersão da affordance da busca por parte do usuário, seja por uma informação dentro de uma edição ou de um número específico, todas as revistas marcaram não-ocorrência. A affordance pesquisar/buscar, tão importante para uma das propriedades representativas do jornalismo em redes digitais - a memória (PALACIOS, 2014; PALACIOS, RIBAS, 2011) - já é tecnicamente possível em publicações deste tipo para tablet e está disponível, por exemplo, na revista espanhola ${ }_{i}$ Hola!.

A marcação de um trecho de uma reportagem, ação que emularia o ato de sublinhar na versão em papel, também esteve ausente entre as publicações analisadas para este artigo, apesar de já ser oferecida em revistas como a francesa Bande à Part. Já a exclusão de uma edição armazenada e o acesso a todas as edições anteriores estiveram presentes nas publicações analisadas.

A atualização dos aplicativos que permitem a circulação e fruição das revistas impacta diretamente em questões específicas da coleção. Primeiro, porque não é possível investigar a performance do aplicativo no momento anterior à sua versão atual, já que o software se renova na loja de aplicativos. Outro ponto diz respeito à perda do controle por parte do proprietário das edições passadas. Após um aprimoramento, uma coleção inteira pode ficar incompatível com a versão atual do aplicativo. Portanto, o controle da coleção que era totalmente dominado pelo colecionador (que antes precisava apenas proteger o papel) passa a ser dividido com os desenvolvedores.

\subsection{Do empréstimo ao compartilhamento}

As possibilidades técnicas observadas nas dinâmicas de funcionamento das mídias sociais foram tomadas emprestadas para o compartilhamento das revistas para tablets. De fato, todas as affordances que descreveremos neste grupo são extensamente discutidas em trabalhos que se dedicam a investigar a relação entre produtos culturais nas redes sociais, como Jenkins, Ford, Green (2013) e Kormelink e Meijer (2014). No entanto, a ocorrência delas em um produto caracterizado como revista reconfigura as formas de interação entre usuários deste objeto jornalístico.

Todas as publicações passaram a inserir botões que permitiam ao usuário o compartilhamento por e-mail ou redes sociais após a primeira edição. A exceção foi a VÀV, revista com data de lançamento no tablet mais recente em relação às outras analisadas, que mantém estes botões desde a estreia. Atualmente, todos os títulos também mantêm canais 
de diálogo abertos por e-mail, formulários ou redes sociais, porém não testamos estas ferramentas.

As inovações verificadas a partir deste conjunto de affordances significaram a obsolescência da concepção de empréstimo deste produto. As revistas para tablets assumiram a característica individualista dos dispositivos móveis alertada por Díaz-Noci (2010). Segundo ele, desde o iPhone (2007), a plataforma móvel já dava sinais de que incentivaria a cultura da propriedade e divergiria da cultura do acesso, promovida pelos computadores. Estes aparelhos concentram informações pessoais, dados bancários, de saúde, agenda telefônica, mensagens, contas de e-mails e de redes sociais. Portanto, o empréstimo de um tablet que tem a personalização como um aspecto definidor é incomum, apesar de possível.

A estratégia explorada pelo jornalismo, especialmente as revistas para tablets, está de acordo com as regras que movimentam a indústria da comunicação móvel. A partir deste ecossistema mercadológico para a plataforma móvel (AGUADO, 2013), os produtores de revistas para tablets exploraram os canais de espalhamento (redes sociais ou e-mails) de forma a permitir que o usuário possa sugerir para um amigo a aquisição da revista.

Outra possibilidade para o compartilhamento das revistas para tablets é o uso das funcionalidades captura de tela (print screen) e o envio por aplicativo de e-mail ou redes sociais. Contudo, esta combinação de affordances (coletar e enviar), além de demandar o uso de aplicativos de terceiros, é bastante limitadora, uma vez que todos os recursos interativos e multimídia que caracterizam estas publicações ficariam comprometidos.

\subsection{A exploração de novos formatos narrativos}

Características, funções e sensores do tablet permitiram que formatos narrativos fossem incrementados (infográficos) ou outras unidades midiáticas entrassem nas revistas, como o vídeo. Saídas de áudio, tela em alta resolução, tela sensível e giroscópio são exemplos de recursos que possibilitaram a inclusão do vídeo, áudio, jogo, infográfico, animações, entre outras formas de contar uma história contribuindo para reforçar mais a concepção da ontologia das emoções de Benetti (2013) para a definição das revistas.

As mudanças começam desde a capa de uma revista, uma espécie de abertura, que pode ser assistida. A VÀV explora o vídeo desde a primeira edição - inclusive em sua estreia ofereceu duas possibilidades de abertura combinando a multimidialidade com a nivelabilidade ao indicar a mudança de orientação da tela. A NGM de janeiro de 2016 usou 
elementos de documentário (trecho de entrevista, voz em off, música instrumental de fundo, legendas e tela com texto) antes de congelar na sua capa.

Figura 1 - As duas capas da $V A ̀ V$ (n⿳⺈⿴囗十) com vídeos visualizados a partir da mudança de orientação do dispositivo
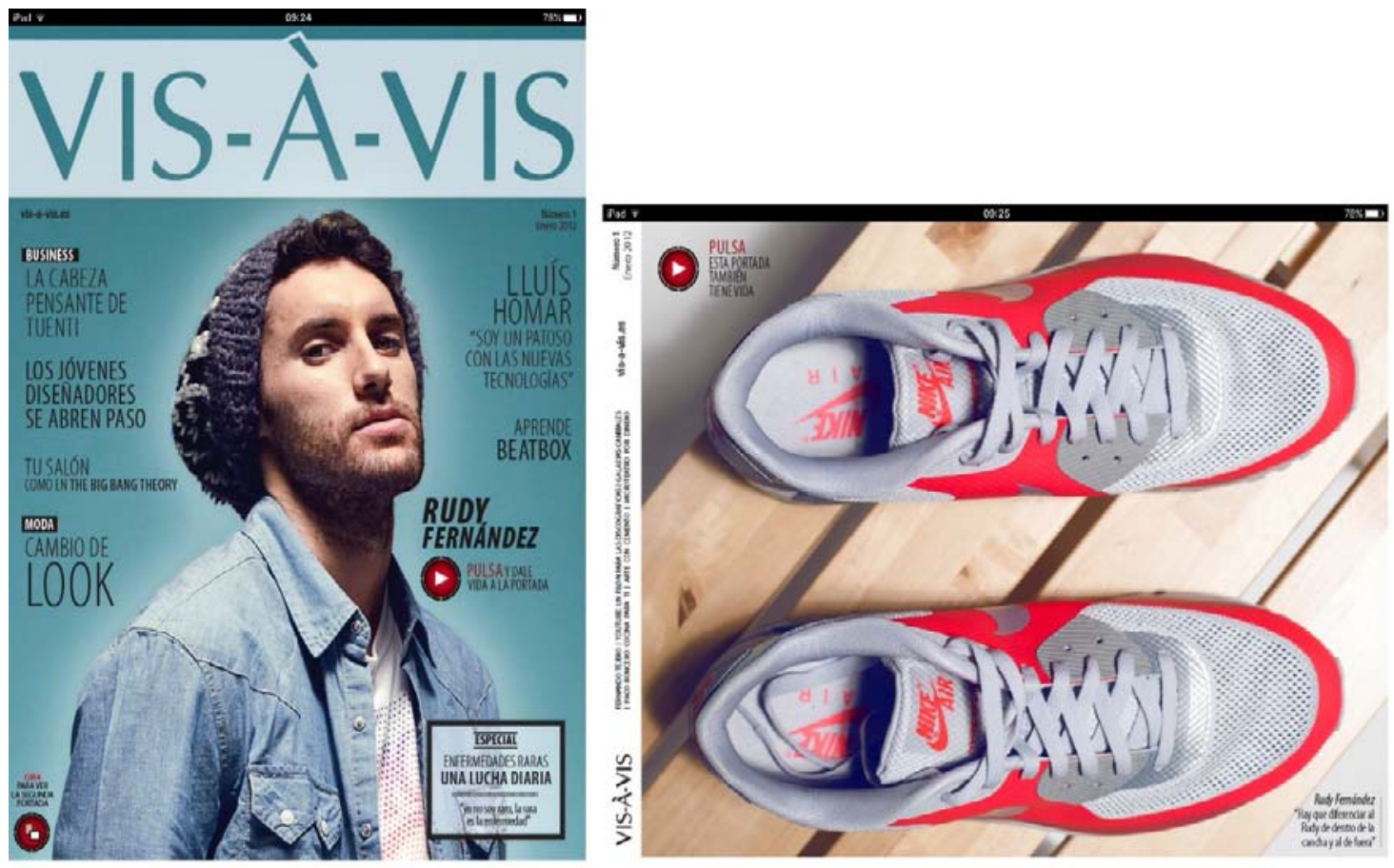

Fonte: Adaptado de Vis-à-Vis (2012).

Gráficos e infográficos interativos também são elementos importantes nestas revistas, pois combinados com funcionalidades dos tablets, modificam a informação a partir da ação do usuário. Eles são resultados de uma produção jornalística configurada a partir da lógica das bases de dados, que demanda o envolvimento do usuário na revelação de informações. Este modelo tem as bases de dados como recurso fundamental desde a organização e estruturação até a apresentação do conteúdo jornalístico (BARBOSA, 2014; BARBOSA, TORRES, 2013). A NGM foi a publicação, entre as três analisadas, que mais explorou estes formatos. Em uma reportagem sobre as espécies de abutres no mundo, na edição de janeiro de 2016, por exemplo, a revista apresentou um infográfico interativo que mostrava os diferentes tipos de animais por continente escolhido pelo usuário através de um toque (Figura 2). 
Figura 2 - Infográfico interativo da $N G M$ sobre as espécies de abutres no mundo

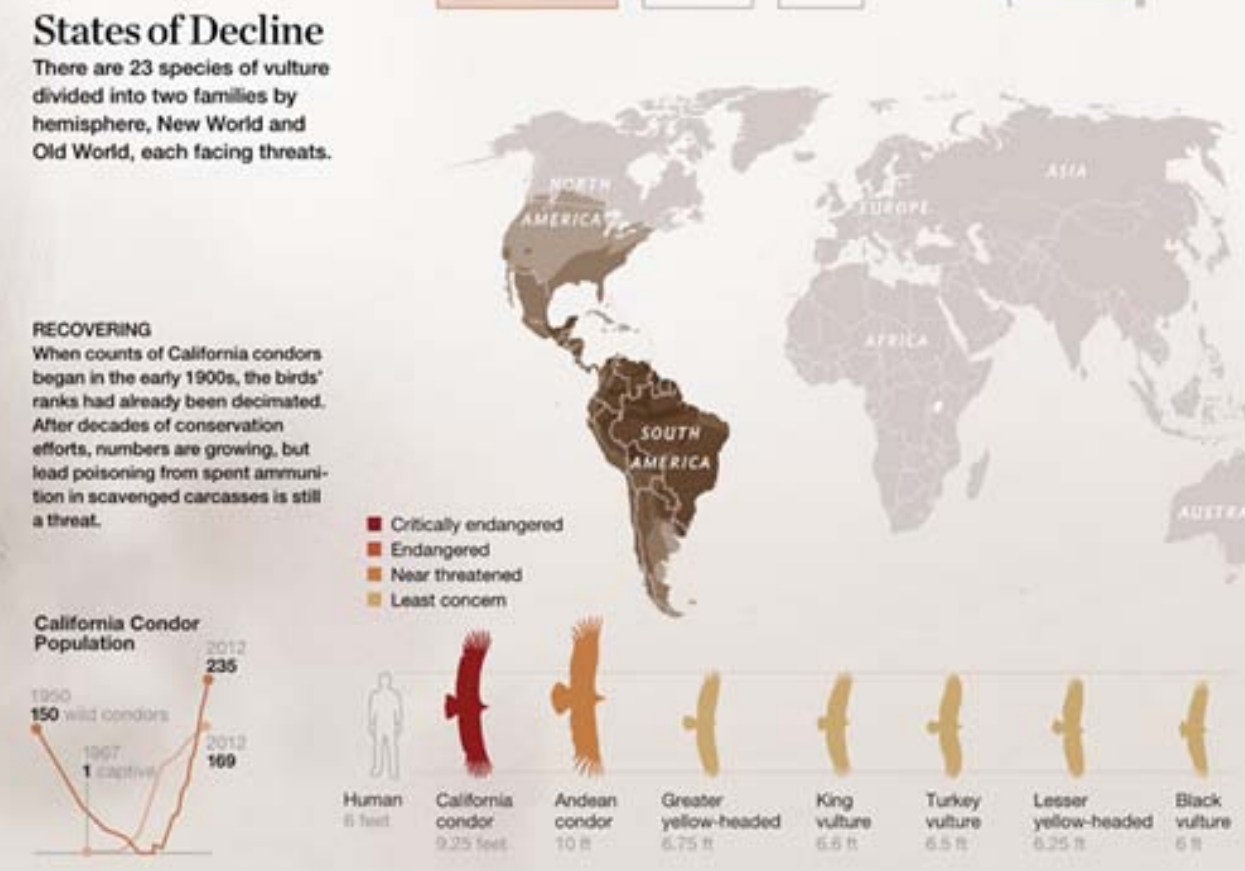

Fonte: Adaptado de National Geographic Magazine (2016).

0 newsgame, união entre o lúdico e a informação, faz com que o usuário cumpra objetivos e descubra informações. Bogost, Ferrari e Schweizer (2010) apresentam uma ampla classificação que contempla desde os jogos de atualidade (mais simples), até os infográficos, os documentais, os quebra-cabeças, os instrutivos e os de comunidades.

Dentre as publicações analisadas, identificamos os seguintes formatos associados à affordance jogar. A Veja explora o quiz em forma de texto sobre os conteúdos da publicação ao final da edição nos números mais recentes. Já a $V A ̀ V$ também usa o quiz em determinadas reportagens, mas de modo mais complexo. Na edição de janeiro, por exemplo, os usuários eram desafiados a adivinhar dentro de um limite de tempo como doze diferentes animais enxergam as cores em um vestido (aquele que em 2015 tornou-se um viral na Internet por provocar ilusão de ótica (MILLS, 2015)). A NGM, por sua vez, mantém uma seção de quebracabeças (NG Daily) com imagens publicadas na edição diariamente. 
Figura 3 - Jogos de passatempo nas revistas: quiz da VÀV (à esquerda) e quebra-cabeças da NGM (à direita)
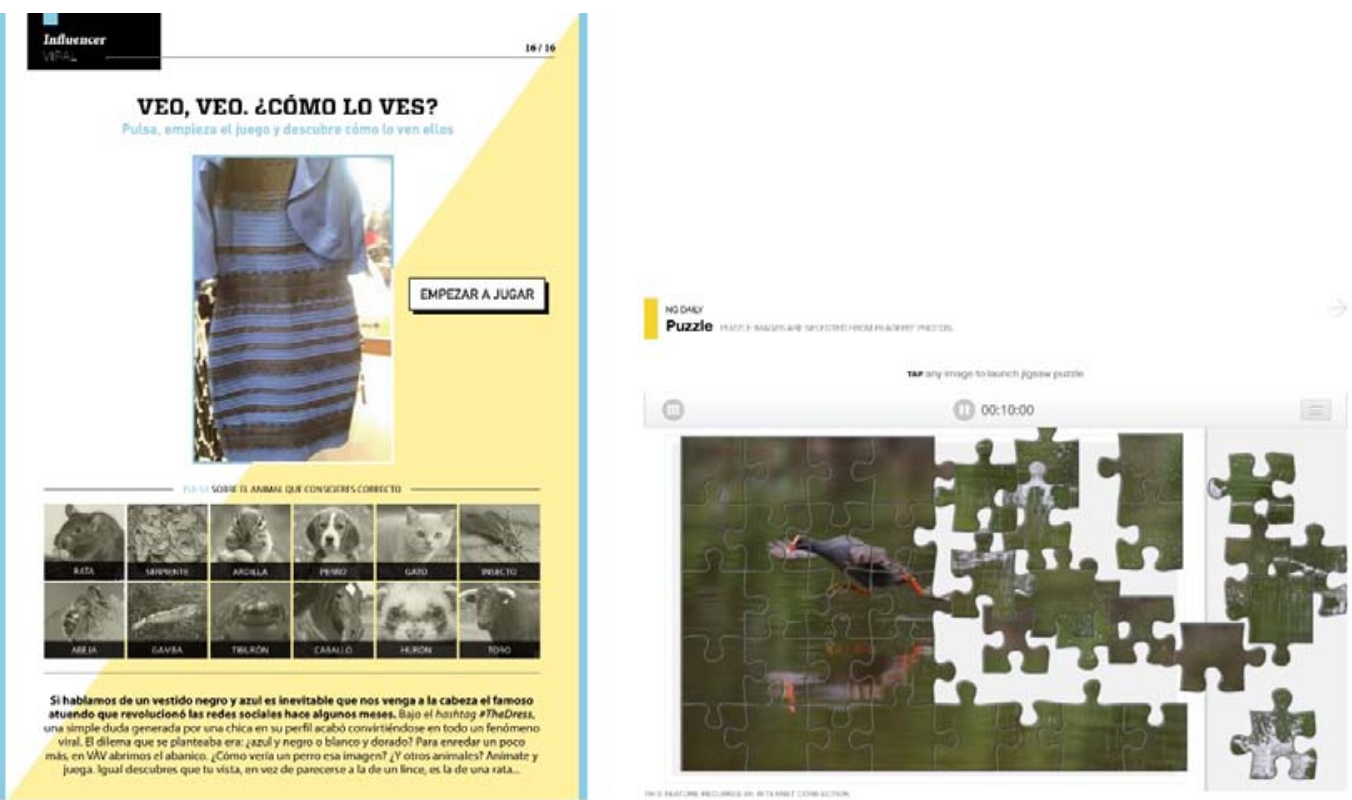

Fonte: Adaptado de Vis-à-Vis (2016) e National Geographic Magazine (2016).

0 ato de ouvir um depoimento, trecho de música, som ambiente, ruídos ou simplesmente a leitura em áudio do texto publicado na revista é uma affordance completamente nova na interação com este tipo de publicação. A Veja não explora este recurso, que pode dar novas dimensões ao usuário sobre determinado conteúdo, como a emoção na voz de quem fala, um som ambiente ou ruído perturbador ou uma música, como

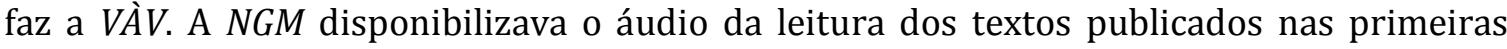
edições.

0 vídeo também desperta emoções e ocupa determinada função na narrativa. Ao apresentar aplicações de diversos formatos midiáticos para o relato de uma história, Kolodzy (2013) explica que esta unidade midiática pode demonstrar, mostrar movimentos e ações, dar um senso de lugar e despertar sentimentos. Nas revistas analisadas, o vídeo apareceu como um elemento ilustrativo $(N G M)$, bastidores de reportagens e entrevistas (VÀV), minidocumentários (NGM), remediados da TV ou web (Veja).

Formatos como a realidade virtual e a realidade aumentada, que enriqueceriam ainda mais a lista de affordances novas ou renovadas das revistas para tablets, não foram verificadas no conteúdo jornalístico nas edições investigadas. Sintetizamos abaixo as affordances encontradas no corpus desta pesquisa a partir de cada grupo descrito. Algumas 
ações listadas representam interações inéditas na relação entre usuários e revistas, enquanto outras foram atualizadas e aprimoradas.

Quadro 4 - Affordances que emergem a partir da interação com as revistas para tablets

\begin{tabular}{|c|c|c|}
\hline $\begin{array}{c}\text { Conjunto de } \\
\text { affordances em } \\
\text { revistas }\end{array}$ & Ações que emergem & Repercussões \\
\hline $\begin{array}{c}\text { Affordances da } \\
\text { operação }\end{array}$ & $\begin{array}{c}\text { Tocar, rolar, deslizar, pinçar, } \\
\text { pressionar, rotacionar, } \\
\text { comprimir, digitar, esfregar, } \\
\text { virar a tela a apertar botões de } \\
\text { volume }\end{array}$ & $\begin{array}{c}\text { Os gestos táteis na tela sensível ao } \\
\text { toque pontuados em Palacios e } \\
\text { Cunha(2012) tornaram os comandos } \\
\text { para interações com os conteúdos das } \\
\text { revistas mais complexos }\end{array}$ \\
\hline Affordances da coleção & $\begin{array}{c}\text { Pesquisar, buscar, armazenar, } \\
\text { acessar, adquirir, descartar, } \\
\text { restaurar, marcar como } \\
\text { favorito e destacar trecho }\end{array}$ & $\begin{array}{c}\text { Melhorias no acesso e aquisição das } \\
\text { revistas, porém os recurso para a } \\
\text { recuperação de informação e a } \\
\text { insegurança da coleção formada } \\
\text { mostram que avanços da plataforma } \\
\text { web não foram agregados }\end{array}$ \\
\hline $\begin{array}{c}\text { Affordances do } \\
\text { compartilhamento }\end{array}$ & $\begin{array}{c}\text { Compartilhar, recomendar, } \\
\text { enviar, encaminhar, dialogar e } \\
\text { comentar }\end{array}$ & $\begin{array}{c}\text { Exploração das dinâmicas das } \\
\text { plataformas social e móvel } \\
\text { substituíram a concepção do } \\
\text { empréstimo pela recomendação para } \\
\text { aquisição de novo exemplar }\end{array}$ \\
\hline $\begin{array}{c}\text { Affordances da } \\
\text { multimidialidade }\end{array}$ & $\begin{array}{c}\text { Ler, assistir, ver, ouvir, jogar } \\
\text { Aprimoramentos e inserção de novas } \\
\text { ações combinadas com affordances da } \\
\text { operação e compartilhamento } \\
\text { substituíram a concepção de consumo } \\
\text { pela interação com os conteúdos } \\
\text { dinâmicos }\end{array}$ \\
\hline
\end{tabular}

Fonte: Elaborado pelos autores.

Algumas das ações listadas já foram reconhecidas nas plataformas web, social, além da móvel e produtos jornalísticos feitos para tablet. Em Kormelink e Meijer (2014, p. 666), foram identificadas 16 ações de usuários com notícias, marcadas pelos verbos "ler, assistir, ver, ouvir, checar, snacking, monitorar, escanear, pesquisar, clicar, usar link, compartilhar, dar likes, recomendar, comentar e votar"10. A proposta de tipologia dos gestos táteis para o controle e comunicação em dispositivos móveis em Palacios e Cunha (2012) também já trazia movimentos apontados, sobretudo no conjunto de affordances da operação em revistas para tablets. Contudo, a complexidade dessas interações e a combinação das affordances para criação de narrativas dinâmicas é que resultam na oferta de publicações originais.

Palacios et al. (2015) apontam que os novos processos de interação e sensorialidades observados nos conteúdos jornalísticos feitos para tablets e smartphones são induzidos por

10 "Reading, watching, viewing, listening, checking, snacking, scanning, monitoring, searching, clicking, linking, sharing, liking, recommending, commenting and voting." (KORMELINK; MEIJER, 2014, p. 666). 
affordances. Mas são as affordances não aparentes e ocultas que são, de fato, "gatilhos para inovação". "Funcionam como portas secretas a serem descobertas e abertas pelo designer, no momento da concepção do produto, ou pelo usuário, através de usos não previstos pelo designer." (PALACIOS et al., 2015, p. 32).

Portanto, determinadas affordances podem se combinar para gerar affordances não aparentes e desencadear inovações mais complexas nas revistas. Além disso, as ações listadas acima dão origem a uma série de repercussões de ordem sensorial em seus interatores - como o ato de jogar que pode despertar a competitividade ou um vídeo que pode emocionar - completamente de acordo com a proposta da ontologia das emoções de Benetti (2013) para as revistas, porém com novas possibilidades narrativas e interativas.

\section{Conclusões}

A análise do corpus e as discussões promovidas a partir do conceito das affordances indicaram que as plataformas móveis, com seus recursos e funcionalidades, têm possibilitado inovações no jornalismo de revista por permitirem a emersão de novas ações ou a atualização de outras na relação com os usuários. Os vários tipos de toques, os áudios, vídeos e os jogos de passatempo são alguns elementos que podem induzir inovações nas narrativas jornalísticas porque tornaram mais complexas as interações entre usuários e as publicações para tablets, segundo a investigação junto ao corpus deste artigo. Entendemos que as revistas se apresentam como um formato potencial para explorar o ecossistema móvel, por conta da flexibilidade deste gênero em narrativas e estética visual, e por oferecerem produtos originais.

Foi possível reconhecer uma maior complexidade nos comandos para a operação destas publicações no tablet em comparação com formatos anteriores, sobretudo com exploração da tactilidade (affordances da operação). Depois, verificamos melhorias no acesso e armazenamento das revistas, embora alguns aspectos ainda possam ser aprimorados, como a memória (affordances da coleção). Além disso, houve uma reconfiguração da concepção de empréstimo para o compartilhamento com vista à aquisição de um novo exemplar pelo caráter pessoal do dispositivo (affordance do compartilhamento). Por fim, destacamos a inserção de novos formatos narrativos ou a renovação de outros que modificaram as formas de interação com as reportagens e que, junto com os recursos e funcionalidades do tablet, podem promover mais envolvimento do usuário com a informação (affordances da multimidialidade). 
Contudo, é preciso pontuar alguns aspectos do cenário contemporâneo deste segmento que apontam no sentido oposto à evolução que observamos. 0 primeiro deles diz


recursos dos tablets para incrementarem seus formatos narrativos, comporem reportagens e ajudarem a formar uma identidade para este tipo de produto jornalístico. No Brasil, por exemplo, grande parte das revistas usa a plataforma móvel apenas como mais um canal de distribuição de suas edições impressas em formato $p d f$ (Época), enquanto outras adaptam os conteúdos da versão em papel para circulação no tablet, com a inserção de mais imagens ou vídeos produzidos para plataformas Web e para TV (Isto É e Veja). Os custos elevados para a produção de conteúdo autóctone para este dispositivo móvel e a transposição de modelos de negócios dos impressos ou da Web ajudam a explicar as dificuldades das organizações jornalísticas (não apenas brasileiras) em investir em inovações neste tipo de produto.

A segunda questão está relacionada a uma tendência de estabilização de um formato de revista para tablet observada a partir da análise restrita às publicações autóctones para dispositivos móveis. A $N G M$ e a $V A ̀ V$ apresentaram produtos atuais bastante semelhantes do ponto de vista da exploração dos recursos do tablet e do próprio design quando comparados às edições de 2013. Isto significa que estas organizações jornalísticas chegaram a um padrão de revistas feitas para os tablets "ideal" para seus modelos de negócios e ambições editoriais. No entanto, notamos que ainda há potencial de inovação com a exploração de formatos como newsgames, a realidade aumentada e virtual. A diversificação da narrativa jornalística nestes produtos autóctones para tablets pode repercutir, inclusive, nos valores historicamente construídos pela comunidade jornalística, como a objetividade, vigilância, precisão e autonomia, na medida em que os recursos e sensores destes dispositivos sejam explorados tanto na produção quanto na reportagem. Este é um dos caminhos futuros para nossa investigação.

O último ponto está relacionado a ausência de novos veículos autóctones para dispositivos móveis, ou a inexistência de evoluções entre os que ainda existem e ao encerramento de outros (os brasileiros Diário do Nordeste Plus (2015) e Globo a Mais (2015); além das revistas inglesa e francesa Ernest Journal (2015) e Rue89 (2014) e da norueguesa Katachi (2013)). O momento contrasta, por exemplo, com a expansão do mercado de aplicativos, que deve dobrar sua receita até 2020 (STATISTA, 2016), e dos 
games para plataforma móvel, que crescerá anualmente 18\% até 2018 (DIGI-CAPITAL, 2015).

Examinamos apenas um aspecto das mudanças no jornalismo móvel de revistas para tablets com o apoio da perspectiva das affordances como indutoras de inovação no produto. No entanto, um conjunto de elementos precisa estar envolvido para que estas publicações originais sejam oferecidas. Diversas perspectivas de estudo podem abordar a inovação no jornalismo, como os novos modelos de negócio, a inserção e atualização de perfis profissionais, as novas tecnologias, as mudanças nas rotinas de trabalho, na interação com os usuários, bem como nas narrativas.

\section{Financiamento}

A pesquisa contou com o apoio de bolsa de mestrado da Coordenação de Aperfeiçoamento de Pessoal de Nível Superior (Capes).

\section{Referências}

AGAMBEN, G. O que é um dispositivo? Outra travessia, Florianópolis, n. 5, p. 9-16, 2005.

AGUADO, J. M. La industria de contenido en la era post-PC: horizontes, amenazas y oportunidades. In: CANAVILHAS, J. (Org.). Notícias em mobilidade: o jornalismo na era dos dispositivos móveis. Covilhã: Universidade da Beira Interior, 2013. p. 5-32.

AGUADO, J. M.; FEIJÓO, C.; MARTÍNEZ, I. J. Contenidos digitales y comunicación móvil: hacia la transformación de internet. Revista Científica de la Asociación Mexicana de Derecho a la Información, Ciudade del México, n. 3, p. 1-15, 2011.

AGUADO, J. M.; GÜERE, H. N. Comunicación móvil, ecosistema digital e industrias culturales. In: AGUADO, J.M.; FEIJÓO, C.; MARTÌNEZ, I.J. (Orgs.). La comunicación móvil: hacia un nuevo ecosistema digital. Barcelona: Editorial Gedisa, 2013. p. 57-78.

BARBOSA, S. Agentes de inovação, renovação e de reconfiguração para o jornalismo em tempos de convergência. Cibercomunicación, Santiago de Compostela, v. 1, n. 1, 2014.

BARBOSA, S. Jornalismo digital em base de dados (JDBD): um paradigma para produtos jornalísticos digitais dinâmicos. 2007. Tese (Doutorado em Comunicação e Cultura Contemporânea) - Faculdade de Comunicação, Universidade Federal da Bahia, Salvador, 2007.

BARBOSA, S.; TORRES, V. 0 paradigma "Jornalismo Digital em Base de Dados": modos de narrar, formatos e visualização para conteúdos. Galáxia, São Paulo, n. 25, p. 152-164, 2013. 
BAUMANN, S. Adapting to the brave new world innovative organisational strategies for media companies. In: ISTORSUL, T.; KRUMSVIK, A. H. (Orgs.). Media innovations: a multidisciplinary study of change. Göteborg: Nordicom University of Gothenburg, 2013. p. 77-92.

BENETTI, M. Revista e jornalismo: conceitos e particularidades. In: TAVARES, F. M. B.; SCHWAAB, R. A revista e seu jornalismo. Porto Alegre: Penso, 2013. p. 44-57.

BOGOST, I.; FERRARI, S.; SCHWEIZER, B. Newsgames: journalism at play. Massachusetts: MIT Press, 2010.

BOLTER, J. D.; GRUSIN, R. Remediation: understanding new media. Cambridge: MIT Press, 2000.

BURUM, I.; QUINN, S. Mojo: the mobile journalism handbook: how to make broadcast videos with an iphone or ipad. [S.l.]: CRC Press, 2015.

CANAVILHAS, J.; SANTANA, D. C. Jornalismo para plataformas móveis de 2008 a 2011: da autonomia à emancipação. Revista Líbero, São Paulo, p. 53-66, 2011.

COLAS, D; GROSRICHARD, A; GAUFEY, A.; WAJEMAN, G. Le jeu de Michel Foucault: dits ecrits tome iii texte ${ }^{\circ}{ }^{2}$ 206. Bulletin Périodique du champ freudien, Paris, n. 10, p. 62-93, 1977.

CUNHA, R. Design de informação em produtos jornalísticos para tablets: uma comparação Brasil-Espanha. 2015. Tese (Doutorado em Comunicação e Cultura Contemporâneas) - Faculdade de Comunicação, Universidade Federal da Bahia, Salvador, 2015.

DAILEY, L.; DEMO, L.; SPILLMAN, M. The convergence continuum: a model for studying collaboration between media newsrooms. Atlantic Journal of Communication, New Jersey, v. 13, n. 3, p. 150-168, 2005.

DÍAZ-NOCI, J. Medios de comunicación en internet: algunas tendencias. El profesional de la información, Barcelona, v. 19, n. 6, p. 561-567, 2010.

DIGI-CAPITAL. Games leaders to dominate $\mathbf{\$ 4 5}$ billion mobile games revenue forecast by 2018. 2015.

FAGERBERG, J. Innovation: a guide to the literature. Oslo: University of Oslo, 2003.

FONSECA, A. A. A inovação no jornalismo em revistas para tablets: uma análise a partir das affordances e da convergência de conteúdos jornalísticos. Dissertação (Mestrado em Comunicação e Cultura Contemporâneas) - Faculdade de Comunicação, UFBA, Salvador, 2015.

FOUCAULT, M. Microfísica do poder. Rio de Janeiro: Edições Graal, 1979. 
FRANCISCATO, C. E. Uma proposta de incorporação dos estudos sobre inovação nas pesquisas em jornalismo. Estudos em Jornalismo e Mídia, Florianópolis, v. 7, n. 1, p. 8-18, 2010.

FREEMAN, C. The determinants of innovation: market demand, technology and the response to social problems. Futures, Oxon, v. 11, n. 3, p. 206-215, 1979.

GAVER, W. W. Technology affordances. In: HUMAN FACTORS IN COMPUTING SYSTEMS CONFERENCE, 1991, New Orleans. Proceedings... New York: ACM, 1991. p. 79-84.

GIBSON, J. J. The ecological approach to visual perception. Boston: Houghton Mifflin. 1979.

GIBSON, J. J. The senses considered as perceptual systems. 1966.

GODIN, B. Innovation: the history of a category. Montreal: Canadian Social Sciences and Humanities Research Council, 2008. (Project on the intellectual history of innovation working paper, n. 1). Disponível em: <http://www.csiic.ca/PDF/IntellectualNo1.pdf>. Acesso em: 9 set. 2015.

GRUBENMANN, S. Innovation in journalism: towards a holistic approach. 2013.

HUTCHBY, I. Technologies, texts and affordances. Sociology, [S.l.], v. 35, n. 2, p. 441-456, 2001.

JENKINS, H.; FORD, S.; GREEN, J. Spreadable media: creating value and meaning in a networked culture. New York: New York University Press, 2013.

JONES, K. S. What is an affordance? Ecological psychology, Philadelphia, v. 15, n. 2, p. 107$114,2003$.

KLINE, S. J.; ROSENBERG, N. An overview of innovation. In: LANDAU, R.; ROSENBERG, N. (Orgs.). The positive sum strategy: harnessing technology for economic growth. Washington: National Academy Press, 1986, p. 275-305.

KOLODZY, J. Practicing convergence journalism: an introduction to cross-media storytelling. London; Nova York: Routledge, 2013.

KORMELINK, T. G.; MEIJER, I. C. Tailor-made news: meeting the demands of news users on mobile and social media. Journalism Studies, Oxon, v. 15, n. 5, p. 632-641, 2014.

MACHADO, E. Creatividad e innovación en el periodismo digital. In: CONGRESO INTERNACIONAL DE CIBERPERIODISMO Y WEB 2.0, 2010, Bilbao. Actas... Bilbao: Universidad del País Basco, 2010. p. 64-72.

MCGRENERE, J.; HO, W. Affordances: clarifying and evolving a concept. In: GRAPHIC INTERFACE, 2000, Montreal. Proceedings... Montreal, 2000. 
MILLS, Chris. Entendendo a ilusão de óptica em forma de vestido que confundiu a internet. Gizmodo, São Paulo, 27 fev. 2015.

MURRAY, J. H. Inventing the medium: principles of interaction design as a cultural practice. Cambridge: MIT Press, 2012.

NATIONAL GEOGRAPHIC MAGAZINE. São Paulo, jan. 2016. Versão para tablets.

NORMAN, D. A. The design of everyday things. New York: Doubleday, 2002.

NORMAN, D. A. The design of everyday things. New York: Basic books, 2013.

PALACIOS, M. Memória: jornalismo, memória e história na era digital. In: CANAVILHAS, J. (Org.). Webjornalismo: 7 características que marcam a diferença. Covilha: Livros LabCom, 2014. p. 89-110.

PALACIOS, M.; CUNHA, R. A tactilidade em dispositivos móveis: primeiras reflexões e ensaio de tipologias. Contemporânea, Salvador, v. 10, n. 3, p. 668-685, 2012.

PALACIOS, M.; BARBOSA, S.; SILVA, F.; CUNHA, R. Aplicativos jornalísticos vespertinos para tablets: cartografia do fenômeno ante o desafio de uma produção original e inovadora. Sur le journalisme, [S.l.], v. 3, n. 2, p. 40-55, 2014.

PALACIOS, M.; BARBOSA, S.; SILVA, F.; CUNHA R. Jornalismo móvel e inovações induzidas por affordances em narrativas para aplicativos em tablets e smartphones. In: CANAVILHAS, J.; SATUF, I. (Orgs.) Jornalismo para dispositivos móveis: produção, distribuição e consumo. Covilhã: Livros LabCom, 2015. p. 7-42.

PALACIOS, M.; RIBAS, B. Ferramenta para análise de memória em cibermeios. In: PALACIOS, M. (Org.). Ferramentas para análise de qualidade no ciberjornalismo. Covilhã: Livros LabCom, 2011. v. 1, p. 183-205.

PAVLIK, J. Media in the digital age. New York: Columbia University Press, 2008.

ROGERS, E. M. Diffusion of innovations. 5. ed. New York: Free Press, 2003.

SCHUMPETER, J. Teoria do desenvolvimento econômico: uma investigação sobre lucros, capital, crédito, juro e o ciclo econômico. São Paulo: Nova Cultural, 1997.

SCOLARI, C. A. eMagazines: la evolución de las interfaces informativas. In: NATANSOHN, G. (Org.). Jornalismo de revista em redes digitais. Salvador: EDUFBA, 2013. p. 191-207.

SILVA, F. F. Jornalismo móvel digital: o uso das tecnologias móveis digitais e a reconfiguração das rotinas de produção da reportagem de campo. 2013. Tese (Doutorado em Comunicação e Cultura Contemporâneas) - Faculdade de Comunicação Social, Universidade Federal da Bahia, Salvador, 2013.

SILVA, F. F. Jornalismo móvel. Salvador: EDUFBA, 2015. 
SOUZA, M. Revistas jornalísticas para tablet: uma análise comparativa entre os modelos convergente e nativo digital. 2013. Tese (Doutorado em Comunicação e Cultura Contemporâneas) - Faculdade de Comunicação, Universidade Federal da Bahia, Salvador, 2013.

STATISTA. Worldwide mobile app revenues in 2015, 2016 and 2020 (in billion U.S. dollars). 2016.

TAVARES, F., SCHWAAB, R. Revista e comunicação: percursos, lógicas e circuitos. In: TAVARES, F. M. B.; SCHWAAB, R. A revista e seu jornalismo. Porto Alegre: Penso, 2013. p. 27-43.

TRAPPEL, J. What to study when studying media and communication innovation? Research design for the digital age. The Journal of Media Innovations, Oslo, v. 2, n. 1, p. 7-22, 2015.

VIS-À-VIS. Madrid, n. 1, jan. 2012. Versão para tablets.

VIS-À-VIS. Madrid, n. 20, dez./jan. 2016. Versão para tablets.

\title{
Affordances inducing innovation in mobile journalism in magazines for tablets
}

\begin{abstract}
This article examines the innovation in mobile journalism starting from the affordance concept applied in the study of tablets magazine in three defined moments between 2010 and 2016. A methodological tool of analysis that aims to explore the four sets of affordances identified was created: operation, collection, sharing and multimediality. Starting from these groups, the emersion of innovators affordances offered by the resources was pointed, and functionalities of the tablets that also allow inedited interactions or renewed ones in the relationship between users and magazines. Among them are: to listen, to watch, to play, and to save. The comparison among the magazines analyzed that stood out for innovation also revealed the trend of stabilization of a format to the exploration of the functionalities of tablets, although we have recognized there are possibilities that were not explored by the products that have the potential to induce innovations.
\end{abstract}

\section{Keywords}

Mobile journalism. Affordances. Innovation. Tablets magazines.

Recebido em 01/11/2016

Aceito em 13/08/2017 